\title{
Comparative Analysis of Agronomic Characters and Saponins Amount of Ginseng in Four Main Agricultural Areas in Yanbian Prefecture
}

\author{
Xue Fang ${ }^{\dagger}$, Jinlei Liu ${ }^{\dagger}$, Xiangguo $\mathrm{Li}^{*}$ \\ Agricultural College, Yanbian University, Yanji City, China \\ Email address: \\ 2420187676@qq.com (Xiangguo Li) \\ ${ }^{*}$ Corresponding author \\ $\dagger$ Xue Fang and Jinlei Liu are co-first authors.
}

To cite this article:

Xue Fang, Jinlei Liu, Xiangguo Li. Comparative Analysis of Agronomic Characters and Saponins Amount of Ginseng in Four Main Agricultural Areas in Yanbian Prefecture. Journal of Diseases and Medicinal Plants. Vol. 5, No. 3, 2019, pp. 45-51.

doi: $10.11648 /$ j.jdmp.20190503.11

Received: May 28, 2019; Accepted: June 29, 2019; Published: July 16, 2019

\begin{abstract}
The farmland ginseng cultivation in Yanbian Prefecture is the main direction in the future. This paper investigates and studies the two main cities and counties in Yanbian Prefecture. The results show that there is no significant difference in root weight and root diameter between the two-year-old farmland, the three-year-old rooting heavy Wang-qing experimental site is significantly higher than other experimental sites, and the three-year-rooting-rough-dunning experimental site is significantly higher than the other three experimental sites. Position. The correlation analysis of the two-year-old soil indicators with root traits and total saponin content showed that total saponin content only showed a significant positive correlation with total phosphorus content; available phosphorus showed a significant positive correlation with root weight and root diameter; root diameter had a significant positive correlation with electrical conductivity. The content of total saponins and total phosphorus showed a highly significant positive correlation, and a highly significant positive correlation with total nitrogen; root weight and $\mathrm{pH}$ showed a highly significant positive correlation; root diameter and available phosphorus showed a highly significant positive correlation, and nitrate nitrogen showed a significant positive correlation. The total saponins content of ginseng in two-year-old farmland showed a significant negative correlation with root weight and root diameter, while the total saponins content in three-year-old farmland showed a very significant negative correlation with root diameter, but no significant correlation with other traits.
\end{abstract}

Keywords: Farmland Ginseng; Saponin Content, Agronomic Traits, Soil Composition

\section{Introduction}

Ginseng is a valuable medicinal material in Northeast China, but the market is in short supply. The state's control over forests is very serious. In order to achieve sustainable development, cutting down forests and planting ginseng are severely restricted, and advocating pollution-free farmland planting ginseng mode is the future development trend [1-2]. Because ginseng has a high requirement on the environment, it should be considered whether it is soil condition, air temperature, humidity or pest control [3]. Soil physical and chemical properties and biological activities are comprehensive evaluation of soil fertility [4-5], Soil N, P and $\mathrm{K}$ are important elements in soil, but soil organic matter is the main source of soil N, P and K [6-8], Studies show that crop yield increases with the increase of nitrogen content [9], Yu Fulai [10] et al. improved the soil by applying fermented corn straw powder, EM bacteria and diatomite. The results showed that the yield of ginseng was significantly increased and the incidence of ginseng was reduced. Therefore, reasonable improvement of farmland soil is an important measure for ginseng cultivation [11].

Ecological environment has a great influence on the growth and development of ginseng, such as temperature, humidity, light and other ecological factors on ginseng characteristics, growth and yield [12], When the soil moisture content is higher than $60 \%$, the root rot of ginseng will be caused, and the pathogenicity will increase. When the soil moisture 
content is lower than $30 \%$, the yield and quality of ginseng will be reduced [13]. Lee et al. showed that the root weight of ginseng seedlings and the number of good ginseng seedlings were positively correlated with the moisture content of seedbed soil [14]. Ginseng likes to be cool and not tolerant to high temperature. The optimum growth temperature of ginseng is about $20^{\circ} \mathrm{C}$. When the temperature is higher than $30^{\circ} \mathrm{C}$ or lower than $10^{\circ} \mathrm{C}$, ginseng goes into dormancy [15-17] Prevention and control of pests and diseases is an important content. In order to achieve sustainable development, it is also a key link to develop bio-fertilizers, new microbial agents and pesticides which are environmentally safe and animal-friendly [18-19], Research shows that green manure can also effectively control pests and diseases [20].

Since 2002, two cities and two counties (Hunchun City, Dunhua City, Antu County and Wangqing County) in Yanbian Prefecture have been designated as the original protected area of ginseng in Changbai Mountain, Jilin Province. Based on the investigation and comparative study of two-year and three-year-old ginseng production areas in four main farmland areas in Yanbian Prefecture, the conditions of ginseng cultivation in farmland were preliminarily explored through the investigation and comprehensive analysis of soil composition, agronomic characteristics and saponin content, which laid a foundation for further research on ginseng cultivation in farmland.

\section{Materials and Methods}

\subsection{Survey of Test Sites}

By visiting and searching, according to the same growth years, live seeding and variety unification as the criteria, the investigation sites were selected in Antu, Wangqing, Dunhua and Hunchun of Yanbian Prefecture, and the two-year-old and three-year-old Damascus cultivars (provenances from Fusong County) were selected as the objects of investigation. The specific conditions of participation were as follows:

Antu Test Site: Located near Haigou Gold Mine, Antu County, the soil type is loam, the former crops are corn and soybean, and the soil improvement methods are pig manure, corn straw, soybean cake and perilla.

Wang Qing Test Site: Located in Shili Ping Village, Dongguang Town, Wangqing County, the soil type is sandy loam, corn and soybean before cropping, and the soil is improved into soybean cake, corn straw, limestone and organic fertilizer.

Dunhua experimental site: located in Hanzhang Township, Dunhua City, the soil type is loam, but the viscous high permeability is relatively poor; the previous crop is corn and soybean, fermented cow dung, corn straw, perilla, limestone for soil improvement.

Hunchun experimental site: located in Hadamen Township, Hunchun City, the soil type is yellow sandy loam, the former crop is corn, and the soil improvement methods are chicken manure, biological fungi and organic fertilizer.

\subsection{Investigation Plan}

At the beginning of April 2017, after determining the test site, there were three test plots for biennial and triennial students in each test site, and no topdressing treatment was done. The size of the plot was 1.4-1.8 m wide and the length was about $5 \mathrm{~m}$. Soil samples were collected by five-point sampling method. When collecting soil samples, surface soil was moved to the soil below Lutou, and each plot was collected three times. In ginseng red fruit stage, the above-ground investigation was carried out at each experimental site. Ten plants were randomly selected from each plot to measure plant height, petiole length, maximum leaf length and width, stem diameter. All measured plants were labeled on the main stem and numbered. At the end of September, all the labeled plants were harvested, and the ginseng roots were washed with running water immediately after harvesting, and the excess water was absorbed by filter paper. The root length, main root length, root diameter and root weight were measured. Then the samples were taken back to the laboratory and dried in a $50 \mathrm{C}$ constant temperature oven. After one week, the dry weight of the samples was taken out and determined. After crushing and sieving (60 meshes), the content of saponins was determined.

\subsection{Determination Method}

The specific determination methods of soil $\mathrm{pH}$ value, conductivity, organic matter, total nitrogen, ammonium nitrogen, nitrate nitrogen, total phosphorus, available phosphorus, total potassium and available potassium refer to the "Agricultural Analysis of Soil" compiled by Bolden. The extraction of ginsenosides mainly refers to the methods of Chinese Pharmacopoeia 2010 Edition [18] and Han Xiao et al. [19]. At the end of September 2017, 15 ginseng plants were randomly collected from each treatment. Plant height, leaf length, leaf width, root length and main root length were measured by ruler, stem diameter and root diameter were measured by vernier caliper, and fresh and dry weight of ginseng roots were measured by electronic balance.

\subsection{Data Processing}

Office Excel 2010 is used to record the original data, SPSS22.0 is used to analyze the difference significance of the data, and Excel is used to draw.

\section{Results and Analysis}

\subsection{Comparison of Soil Physical and Chemical Properties}

\subsubsection{Comparison Between Conductivity and Soil pH}

By comparing and analyzing the soil conductivity of different test points (Figure 1), it can be seen that the soil conductivity of Wangqing test point in two-year-old is significantly lower than that of the other three test points, and there is no significant difference among the other three areas; the soil conductivity of Wangqing test point in three-year-old is significantly different from that of the other three test points, 
and there is no significant difference between Antu test point and Dunhua test point. different. It was found that the $\mathrm{pH}$ of each pilot project was different, mainly determined by the way of soil improvement and soil quality itself. The $\mathrm{pH}$ of each region was below 7 , indicating that the soil was still acidified (Figure 2). There are significant differences between the two-year-old farmland $\mathrm{pH}$ Antu test site and the other three test sites. In the three-year-old, the soil $\mathrm{pH}$ of Wangqing test site is significantly higher than that of the other three test sites, and there are significant differences. There is no significant difference between Wangqing test site and Dunhua test site.

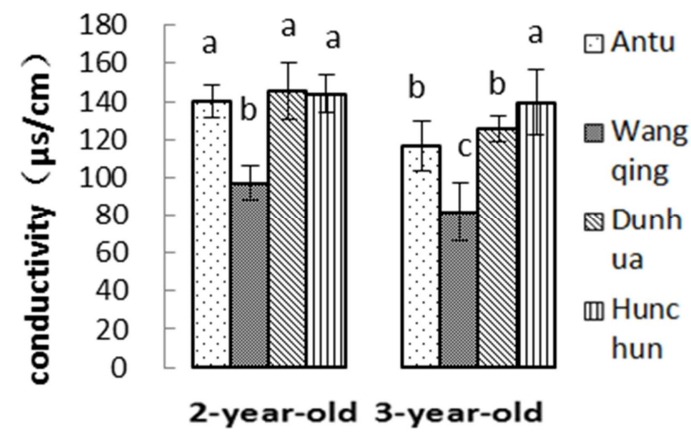

Figure 1. Comparison of soil conductivity at different test sites.

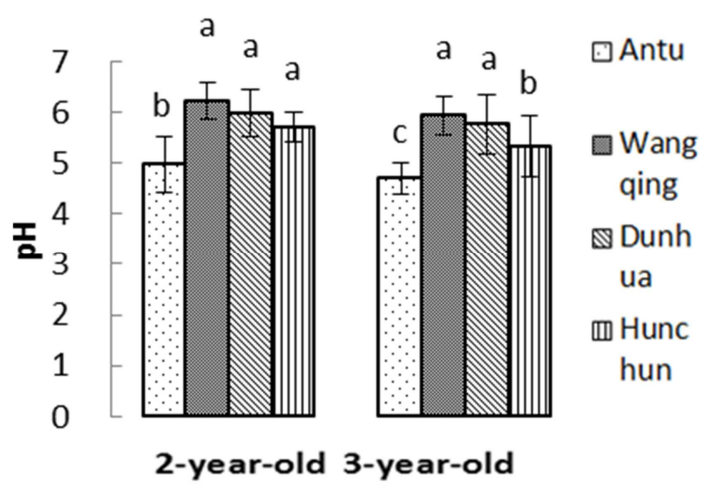

Figure 2. Comparison of soil pH in different test sites.

Note: Significant differences in the representation of different lower-case letters $(\mathrm{p}<0.05)$, same as below.

\subsubsection{Comparison of Soil Nitrogen Contents}

A comparative analysis of total nitrogen content in soils of each test site (Figure 3) shows that the total nitrogen content in soil of Antu and Wangqing test sites is significantly higher than that of Dunhua and Hunchun test sites in two years, and there is no significant difference between Antu test site and Wangqing test site, and there is no significant difference between Dunhua test site and Hunchun test site. The soil total nitrogen content at the site was the highest. Figure 4 shows that there are significant differences in nitrate nitrogen content between two-year-old ginseng soil, Wangqing test site and the other three test sites, but there is no significant difference among them. The nitrate nitrogen content of three-year-old ginseng soil is significantly lower than that of two-year-old ginseng soil, Wangqing test site is significantly lower than that of other three areas.

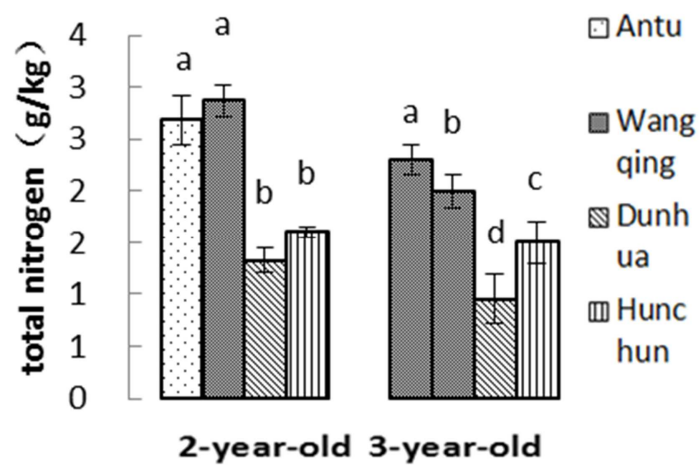

Figure 3. Comparison of soil total nitrogen content in different experimental sites.

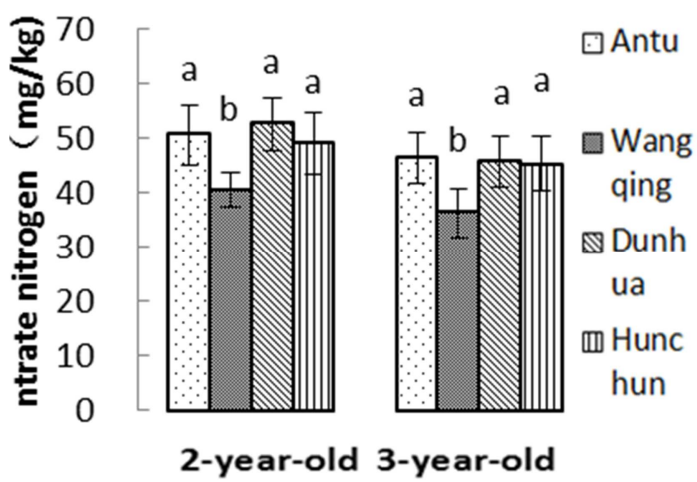

Figure 4. Comparison of soil ntrate nitrogen contents at different test sites.

\subsubsection{Comparison of Phosphorus and Potassium Contents in Soils}

Through the comparative analysis of the total phosphorus content in the soil of each pilot project (Figure 5), we can see that the total phosphorus content of biennial soils is not significantly different in the other three areas except Dunhua test site, Wangqing test site and Hunchun test site, which are significantly higher than Dunhua test site and Hunchun test site in three years. Figure 6 shows that the content of available phosphorus in biennial soils in Antu test site is significantly lower than that in other three areas, and there are significant differences with other three areas. There is no significant difference between Dunhua test site and Hunchun test site. The content of available phosphorus in three-year-old soils in different regions is basically the same as that in two-year-old soils. Through the comparative analysis of the total potassium content in the soils of each pilot project (Figure 7), it can be seen that the total potassium content in the two-year-old soil in Dunhua experimental site is significantly higher than that in the other three areas, and there are significant differences between the three areas. In the three-year-old, the total potassium content in the Antu experimental site is significantly higher than that in the other three areas, while there is no difference among the Wangqing experimental site, Dunhua experimental site and Hunchun experimental site. Significant difference. 


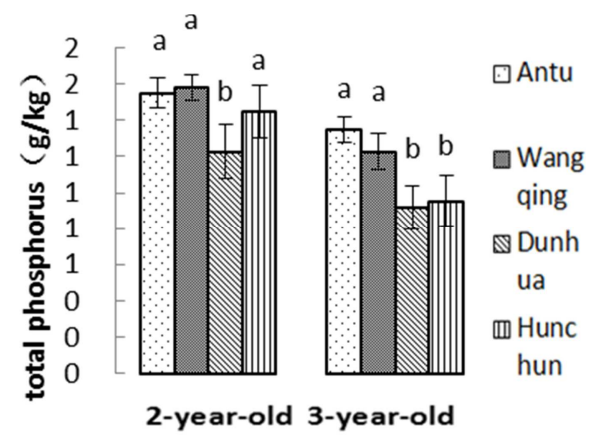

Figure 5. Comparison of soil total phosphorus content in different test sites.

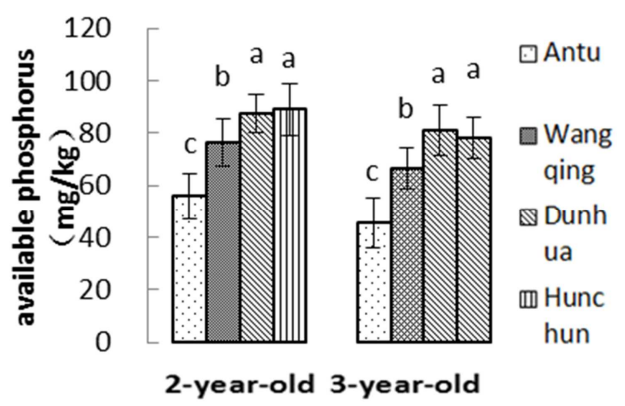

Figure 6. Comparison of soil available phosphorus content in different test sites.

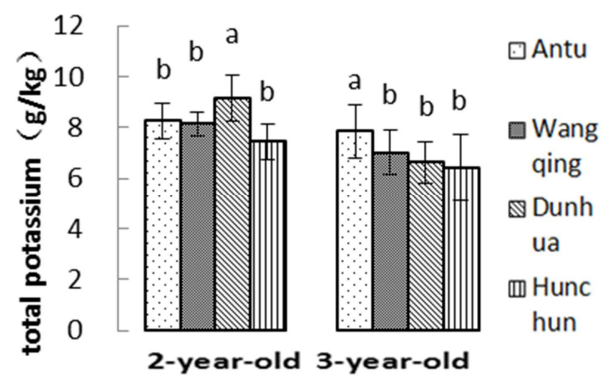

Figure 7. Comparison of soil total potassium content in different experimental sites.

\subsection{Comparison of Agronomic Characters of Ginseng}

\subsubsection{Comparison of the Growing Conditions of the Upper Part of Ginseng}

Through comparative analysis of the above-ground parts of two-year-old farmland ginseng in each test site (Table 1), the results showed that the plant height of Dunhua test site was significantly lower than that of the other three areas, and there was no significant difference among the three areas; the stem diameter of Antu test site and Hunchun test site was significantly thicker than that of Wangqing test site and Dunhua test site; the petiole length of Antu test site was significantly longer than that of other three areas, Wangqing test site and Hunchun test site. There was no significant difference between Dunhua test site and Hunchun test site in petiole length.

Leaf length and leaf width can reflect the size of ginseng leaves, and indirectly reflect the dry matter accumulation rate of photosynthesis. Through comparison, it can be concluded that the leaf length and leaf width of Wangqing and Dunhua experimental sites are significantly higher than that of Antu and Hunchun experimental sites, while there is no significant difference between Wangqing and Dunhua experimental sites, and there is no significant difference between Antu experimental sites and Hunchun experimental sites.

Through comparative analysis of the aboveground parts of three-year-old ginseng in each experimental site (Table 2), the results showed that the aboveground characteristics of Wangqing experimental site were significantly higher than those of other three areas, and there was no significant difference between the leaf width of Dunhua experimental site and Wangqing experimental site, and the characteristics of Wangqing experimental site were better by comparison.

\subsubsection{Comparison of Underground Growth of Panax Ginseng}

Table 3 shows that there is no significant difference in root diameter, root length, main root length and root weight among the four test sites of 2-year-old ginseng. The drying rate of Wangqing test site and Dunhua test site is slightly higher than that of the other two test sites, and there is significant difference between Antu test site and the other three test sites. Table 4 shows that the root thickness of 3-year-old ginseng is lower than that of the other three test sites, and that of Dunhua test site. The root length of Wangqing test site is shorter than that of other three test sites and has significant difference. The root weight of Wangqing test site is greater than that of other three areas. There is significant difference between Antu test site and other three areas. The drying rate of Wangqing test site and Dunhua test site is higher than that of other two test sites.

Table 1. Comparison of shoot growth of two-year-old ginseng in different experimental sites.

\begin{tabular}{llllll}
\hline Test site & Height $(\mathbf{c m})$ & Stem diameter $(\mathbf{c m})$ & Leaf length $(\mathbf{c m})$ & Leaf width $(\mathbf{c m})$ & Petiole length $(\mathbf{c m})$ \\
\hline Antu & $6.43 \mathrm{a}$ & $2.25 \mathrm{a}$ & $5.34 \mathrm{~b}$ & $2.73 \mathrm{~b}$ & $6.06 \mathrm{a}$ \\
Wangqing & $5.83 \mathrm{a}$ & $1.94 \mathrm{~b}$ & $6.63 \mathrm{a}$ & $3.12 \mathrm{a}$ & $4.45 \mathrm{~b}$ \\
Dunhua & $3.81 \mathrm{~b}$ & $1.96 \mathrm{~b}$ & $6.45 \mathrm{a}$ & $3.33 \mathrm{a}$ & $4.96 \mathrm{~b}$ \\
Hunchun & $5.70 \mathrm{a}$ & $2.40 \mathrm{a}$ & $4.80 \mathrm{~b}$ & $2.10 \mathrm{~b}$ & $3.30 \mathrm{c}$ \\
\hline
\end{tabular}

Note: Different lowercase letters in the same column mean significant difference $(\mathrm{p}<0.05)$, same as below.

Table 2. Comparison of shoot growth of three-year-old ginseng in different experimental sites.

\begin{tabular}{llllll}
\hline Test site & Height $(\mathbf{c m})$ & Stem diameter $(\mathbf{c m})$ & Leaf length $(\mathbf{c m})$ & Leaf width $(\mathbf{c m})$ & Petiole length $(\mathbf{c m})$ \\
\hline Antu & $13.83 \mathrm{~b}$ & $3.6 \mathrm{~b}$ & $7.90 \mathrm{~d}$ & $4.31 \mathrm{~b}$ & $7.08 \mathrm{~b}$ \\
Wangqing & $17.74 \mathrm{a}$ & $4.51 \mathrm{a}$ & $12.36 \mathrm{a}$ & $5.12 \mathrm{a}$ & $7.94 \mathrm{a}$ \\
Dunhua & $8.8 \mathrm{c}$ & $2.75 \mathrm{c}$ & $10.78 \mathrm{~b}$ & $4.92 \mathrm{a}$ & $5.92 \mathrm{c}$ \\
Hunchun & $12.71 \mathrm{~b}$ & $3.7 \mathrm{~d}$ & $9.15 \mathrm{c}$ & $4.48 \mathrm{~b}$ & $6.51 \mathrm{~b}$ \\
\hline
\end{tabular}


Table 3. Comparison of shoot growth of 2-year-old ginseng in different experimental sites.

\begin{tabular}{llllll}
\hline Test site & Root diameter $(\mathbf{c m})$ & Root length $(\mathbf{c m})$ & Main root length $(\mathbf{c m})$ & Root weight $(\mathbf{g})$ & Dry density $(\mathbf{g})$ \\
\hline Antu & $10.74 \mathrm{a}$ & $10.21 \mathrm{a}$ & $4.36 \mathrm{a}$ & $4.01 \mathrm{a}$ & $27.77 \mathrm{~b}$ \\
Wangqing & $10.76 \mathrm{a}$ & $11.98 \mathrm{a}$ & $3.94 \mathrm{a}$ & $4.16 \mathrm{a}$ & $30.14 \mathrm{a}$ \\
Dunhua & $11.77 \mathrm{a}$ & $11.35 \mathrm{a}$ & $4.46 \mathrm{a}$ & $4.42 \mathrm{a}$ & $30.86 \mathrm{a}$ \\
Hunchun & $11.02 \mathrm{a}$ & $10.44 \mathrm{a}$ & $4.17 \mathrm{a}$ & $4.23 \mathrm{a}$ & $29.73 \mathrm{ab}$ \\
\hline
\end{tabular}

Table 4. Comparison of shoot growth of three-year-old ginseng in different experimental sites.

\begin{tabular}{llllll}
\hline Test site & Root diameter $(\mathbf{c m})$ & Root length $(\mathbf{c m})$ & Main root length $(\mathbf{c m})$ & Root weight $(\mathbf{g})$ & Dry density $(\mathbf{g})$ \\
\hline Antu & $13.13 \mathrm{c}$ & $20.46 \mathrm{a}$ & $6.80 \mathrm{~b}$ & $15.32 \mathrm{c}$ & $29.25 \mathrm{~b}$ \\
Wangqing & $16.71 \mathrm{~b}$ & $20.35 \mathrm{a}$ & $9.07 \mathrm{a}$ & $22.09 \mathrm{a}$ & $31.93 \mathrm{a}$ \\
Dunhua & $19.72 \mathrm{a}$ & $15.94 \mathrm{~b}$ & $5.44 \mathrm{c}$ & $20.38 \mathrm{ab}$ & $32.31 \mathrm{a}$ \\
Hunchun & $17.54 \mathrm{~b}$ & $18.89 \mathrm{a}$ & $6.24 \mathrm{~b}$ & $19.24 \mathrm{~b}$ & $31.01 \mathrm{~b}$ \\
\hline
\end{tabular}

\subsection{Comparison of Ginsenoside Contents}

The average values of ginsenoside content in biennial and triennial farmland in each experimental site are shown in Figure 8. The content of $\mathrm{Rg} 1, \mathrm{Rb} 1, \mathrm{Rb} 2$ and $\mathrm{Rd}$ in biennial and triennial farmland in Antu experimental site are higher than those in other three areas. The content of Re, Rf and Rc in other areas are higher than those in Wangqing experimental site; the content of total saponin Antu is the highest, followed by Wangqing.

The content of triennial monomer saponins in Figure 9 Antu is the highest in $\mathrm{Re}, \mathrm{Rc}, \mathrm{Rb} 2$ and $\mathrm{Rd}$, while the content of $\mathrm{Rg} 1$ and $R f$ is the highest in Wangqing, and the content of Rb1 is the highest in Hunchun. The content of total saponins in Antu is the highest, followed by Wangqing, which is basically the same as that in two-year-old.

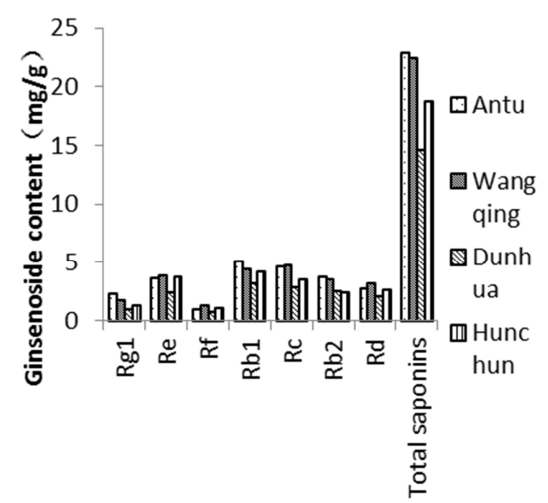

Figure 8. Content of Ginsenoside in Biennial Ginseng.

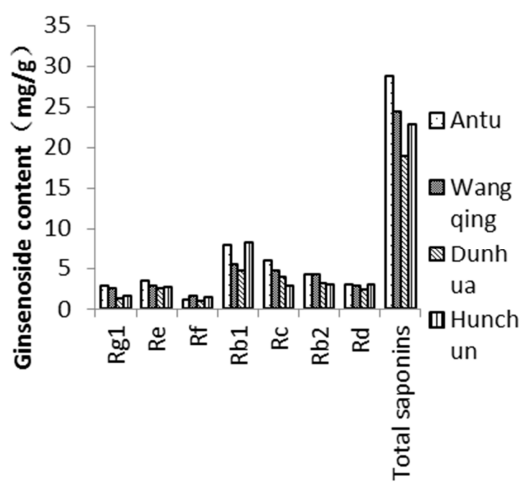

\subsection{Relevance Analysis of Indicators}

\subsubsection{Correlation Analysis of Total Saponins Content and Agronomic Traits}

The results of correlation analysis between total saponins content and agronomic traits of two-year-old farmland ginseng (Figure 10) showed that there was a high correlation between total saponins content and root weight and root diameter. The correlation coefficient between total saponins content and root weight was -0.67 , which showed a highly significant negative correlation with root diameter, and the correlation coefficient was -0.83 , but no significant correlation with other sexual transformation.

The results of correlation analysis of total saponins content and agronomic traits of three-year-old farmland ginseng (Figure 11) showed that root diameter was highly negatively correlated with total saponins content, and the correlation coefficient was -0.87 . There was no significant correlation with other traits.

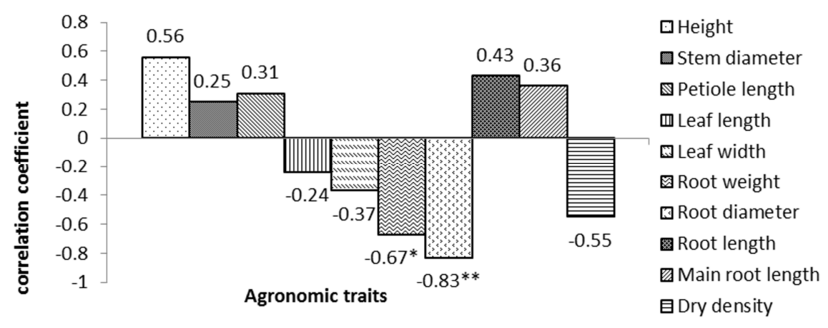

Figure 10. Correlation analysis of total saponin content and Agronomic Traits in two-year-old.

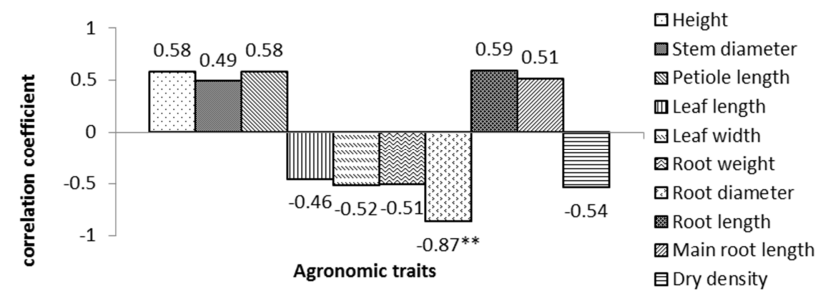

Figure 11. Correlation analysis of total saponins content and Agronomic Traits in three-year-old.

Note:* Significant difference in representation; ** Significant difference in very representation. 


\subsubsection{Correlation Analysis of Soil Indicators with Root Characters and Total Saponins Content}

Figure 12 showed that there was a significant high correlation between two-year rooting diameter and electrical conductivity, with a correlation coefficient of $0.717 ; \mathrm{pH}$ showed a high positive correlation with root weight, showing a moderate positive correlation with root weight $(r=0.826, r$ $=0.689$ ); total nitrogen and total saponins showed a moderate positive correlation with a correlation coefficient of 0.673 ; available phosphorus showed a high correlation with root weight, root thickness and root dryness. Positive correlation was found $(\mathrm{r}>0.70)$, and no significant correlation was found in the rest.

From Figure 13, it can be seen that three-year-old $\mathrm{pH}$ is highly positively correlated with root weight and drying rate, with correlation coefficients of 0.788 and 0.722 , respectively; total nitrogen and total saponin content show a highly positive correlation, with correlation coefficient of 0.728 ; nitrate nitrogen is highly positively correlated with root diameter $(\mathrm{r}=0.727)$; total phosphorus is highly positively correlated with total saponin content $(\mathrm{r}=0.809)$; available phosphorus is highly correlated with root diameter and drying rate. There was a highly positive correlation between root weight and root weight, and the rest showed a significant correlation.

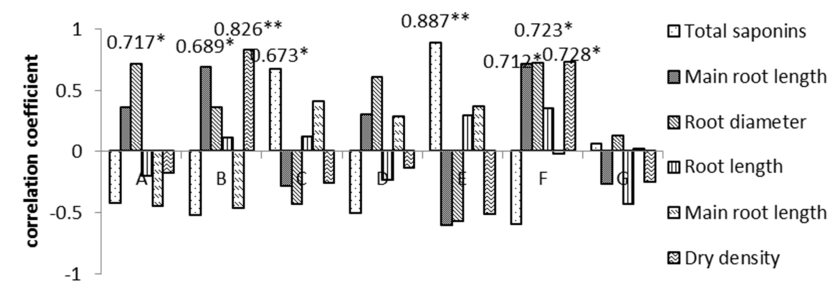

Figure 12. Correlation Analysis of two-year-old Soil Indicators with Root Characters and Total Saponins Content.

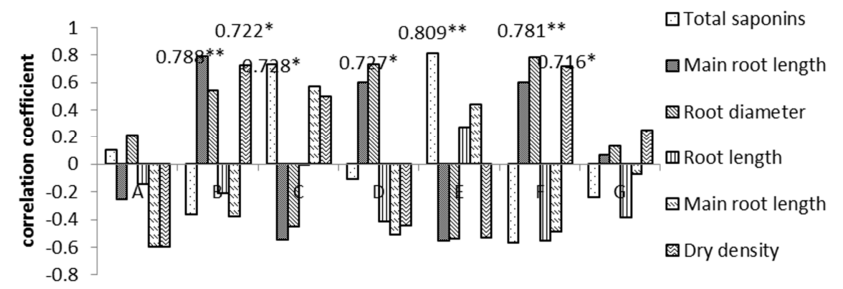

Figure 13. Correlation analysis of three-year-old soil index with root traits and total saponins content.

Note: A-conductivity B-pH C-total nitrogen D-Nitrate nitrogen E-total phosphorus F-Available phosphorus G-Total potassium.

\section{Discussion}

Soil indices are very important factors in ginseng cultivation. In comparison of $\mathrm{pH}$ values, the $\mathrm{pH}$ values of Wangqing and Dunhua test sites are significantly higher than those of the other two sites. The main reason may be that limestone is added to soil improvement, which has a certain impact on ginseng growth and development. Appropriate $\mathrm{pH}$ is helpful to improve the utilization efficiency of soil nutrients by plants. The results of correlation analysis between soil and agronomic ginseng showed that there was a significant positive correlation between soil $\mathrm{pH}$ and root weight in biennial and triennial soils, indicating that soil $\mathrm{pH}$ had a certain effect on the yield of Agronomic ginseng. Zhao Shoujing [21] et al. showed that the suitable range of soil $\mathrm{pH}$ for ginseng cultivation was between 5.5 and 7. Through analysis, it can be seen that soil $\mathrm{pH}$ below 5 has a more obvious effect on the root weight of ginseng in farmland.

There is a highly positive correlation between total nitrogen and total saponin content. It can be seen that increasing total nitrogen content can effectively increase total saponin content. Wang Tianle [22] et al. found that the ratio of nitrogen, phosphorus and potassium is different in different nutrient content. The comparison of nitrate nitrogen content shows that the content of Wangqing experimental site in Biennial and triennial years is lower than that in other three areas. The improvement of Wangqing experimental site is as follows: Farmer manure was used, which was similar to the results of Zhangdi [23]. It showed that the application of farmer manure had a certain effect on nitrate nitrogen content. The content of total saponins and mono saponins $\mathrm{Rg} 1, \mathrm{Rf}, \mathrm{Rb} 1$ and $\mathrm{Rb} 2$ in two-year-old and three-year-old regions were lower than that in three-year-old regions, which indicated that the content of these four mono saponins increased with the increase of growth years, but the content of Re in three-year-old was lower than that in two-year-old Lin Hongmei [24] et al. The conclusion is basically consistent with that of this paper, but the conclusion of Rb2 is contrary, which needs further study.

The results showed that the content of total saponins in biennial and triennial farmland was different in different regions. The correlation analysis of agronomic traits and saponins content showed that the content of total saponins was only negatively correlated with root diameter, and the correlation coefficients were -0.83 and -0.87 , respectively, showing strong correlation, but not with other agronomic traits. The results of $\mathrm{Li}$ et al [25] are consistent.

\section{Conclusion}

This paper investigates four main farmland production areas in Yanbian Prefecture and finds that there is no significant difference in ginseng root weight and root diameter between two-year-old farmland and three-year-old farmland. The three-year-old rooting heavy Wangqing test site is significantly higher than other test sites, and the three-year-old rooting rough dunning test site is significantly higher than the other three test sites. The total saponin Antu test site is high. The correlation analysis of the two-year-old soil indicators with root traits and total saponin content showed that total saponin content only showed a significant positive correlation with total phosphorus content; available phosphorus showed a significant positive correlation with root weight and root diameter; root diameter had a significant positive correlation with electrical conductivity. The content of total saponins and total phosphorus showed a highly significant positive correlation, and a highly 
significant positive correlation with total nitrogen; root weight and $\mathrm{pH}$ showed a highly significant positive correlation; root diameter and available phosphorus showed a highly significant positive correlation, and nitrate nitrogen showed a significant positive correlation. The total saponins content of ginseng in biennial farmland showed a significant negative correlation with root weight and root diameter, while the total saponins content of ginseng in triennial farmland showed a very significant negative correlation with root diameter, but no significant correlation with other traits.

\section{Acknowledgements}

This study was supported by a grant from College-Enterprise Cooperation Project of Yanbian University (No. 2018 (43)).

\section{References}

[1] Shen L, Xu J, Dong L L, et al. Cropping system and research strategies in Panax ginseng [J]. China Journal of Chinese Materia Medica, 2015, 40 (17): 3367- 3373.

[2] Niu W H, Xu J, Dong L L, et al. A Research Progress on the Vantage of Cultivation of Ginseng in Farmlands [J]. World Science and Technology, 2016, 18 (11): 1981-1987.

[3] Mu S Z, Yang X W, Di Y T, et al. Secophnane-type alkaloids from Daphniphyllum oldhami [J]. Chemistry \& Biodiversity, 2007, 4 (2): 129-138.

[4] Bulluck L R, Brosius M, Evanylo G K, et al. Organic and synthetic fertility amendments influence soil microbial, physical and chemical properties on organic and conventional farms [J]. Applied Soil Ecology, 2002, 19 (2): 147-160.

[5] Liu B, Tu C, Hu S J, et al. Effect of organic, sustainable, andconventional management strategies in grower fields on soil physical, chemical, and biological factors and the incidence of Southern blight [J]. Applied Soil Ecology, 2007, 37 (2): 202-214.

[6] Zhang Y, Pang X Y, Bao W K, et al. A Review of Soil Organic Matter and Its Research Methods [J]. World Science and Technology Research and Development, 2005 (5): 78-84.

[7] Vladimir SM, Juriga J, Jerzy J, et al. How relationships between soil organic matter parameters and soil structure characteristics are affected by the long-term fertilization of a sandy soil [J]. Geoderma, 2019 (5): 75-84.

[8] Giller K E, Tittonell P, Rufino M C, et al. Communication complexity: integrated assessment of trade-offs concerning soil fertility management within African farming systems to support innovation and development [J]. Agricultural Systems, 2011, 104 (2): 191-203.

[9] Zhong Y, Fan J, Wang D, et al. Genotypic differences in grain yield and physiologyical nitrogen use efficiency among rice cultivars [J]. Pedosphere, 2009, 19 (6): 681-691.

[10] Yu F L, Bao J S, Ma Q L, et al. Effects of application of three soil conditioners on yield and quality of farmland-cultured ginseng [J]. Techan Yanjiu (Special Wild Economic Animal and Plant Research), 2009 (2): 17-20.
[11] Xu J, Dong L L, Wang R, et al. Soil improvement promoted micro-ecology of farmlands for ginseng cultivation [J]. Zhongguo Zhongyao Zazhi (China Journal of Chinese Materia Medica), 2017, 42 (5): 875-881.

[12] Mu S Z, Yang X W, Di Y T, et al. Secophnane-type alkaloids from Daphniphyllum oldhami [J]. Chemistry \& Biodiversity, 2007, 4 (2): 129-138

[13] Zhang J, Wang ZX, Zhang HY, et al. Artificial Cultivation Techniques of Ginseng in Changbai Mountain [J]. Chinese Horticulture Abstracts, 2014 (1): 218.

[14] Lee S W, Kim C G, Hyun D Y, et al. Effect of light transmission ratio and soil moisture content on growth characteristics of seedling in Panax ginseng C. A. Mey.[J]. Korean J Med Crop Sci, 2008, 16 (4): 207.

[15] Zhang Q S, Wang F. Research on the Environment of Ecological Climate and Adaptability toCultivated Region in Ginseng [J]. Series of Plant Ecology and Geobotany, 1984, 8 (2): 85 .

[16] Lee S W, Hyun D Y, Park C G, et al. Effect of soil moisture content on photosynthesis and root yield of Panax ginseng C. A. Mey. Seedling [J]. Korean J Med Crop Sci, 2007, 15 (6): 367.

[17] Choi J E, Lee N R, Jo S R, et al. Effects of various bed soil sub-strates on the growth and yield of 2-year-old ginseng grown 8 in the closed plastic house [J]. Korean J Med Crop Sci, 2012, 20 (4): 217.

[18] Bonanomi G, Del S G, Mazzoleni S, et al. Autotoxicity of decaying tomato residues affects susceptibility of tomato to Fusarium wilt [J]. J Plant Pathol, 2007, 89 (2): 219.

[19] Chung Y R, Kim H J, Park K J. Comparison of rhizosphere environments in soils suppressive and conducive to ginseng root rot [J]. Korean J Plant protect, 1984, 22 (3): 142.

[20] Lamondia J A. Management of lesion nematodes and potato early dying with rotation crops [J]. J Nematol, 2006, 38 (4): 442.

[21] Zhao S J, Sun S G, Wang R S, et al. Correlation and Path Analysis of Main Agronomic Characters of Ginseng [J]. Journal of Chinese Medicinal Materials, 1991 (10): 8-10.

[22] Wang T L, Wei Z J, Yan R R, et al. Effects of Nitrogen, Phosphorus and Potassium Additionon Soil Nutrient [J]. Northern Horticulture, 2017 (23): 147-154.

[23] Zhang D, Zhao M Q, Niu M F, et al. Effects of Different Organic Manure Rate on NO3--N Distribution under Depth Profile of Protected Cultivation Soil [J]. Chinese Journal of Soil Science, 2011, 42 (5): 1148-1152.

[24] Lin H M. Effect of Ecological Factors on Ginsenoside Content of Panax ginseng and the Expression of Key Biosynthesis Enzymes Genes [D]. Changchun: Jilin Agricultural University, 2016.

[25] Li XG, Kang SJ, Han JS, et al. Effects of root diameter within different root parts on ginsenoside composition of Yunpoong cultivar in Panax ginseng C. A. Meyer [J]. Korean J Med Crop Sci, 2009, 17 (6): 452-457. 